\title{
Uso de probióticos y ácidos orgánicos como estimulantes del desarrollo de aves de engorde: artículo de revisión
}

\author{
Use of probiotics and organic acids as stimulants of the developpment of broilers: review article \\ Uso de probióticos e acidos organicos como estimilantes de desenvolvimiento em broilers: artigo de revisao

\section{Franklin Alfredo Iñiguez Heredia} \\ franklin.iniguez@ucacue.edu.ec \\ https://orcid.org/0000-0002-5082-1611 \\ Universidad Católica de Cuenca, Cuenca, Ecuador \\ Xavier Esteban Espinoza Bustamante \\ xavier.espinoza.47@ucacue.edu.ec \\ https://orcid.org/0000-0002-2430-7811 \\ Universidad Católica de Cuenca, Cuenca, Ecuador
}

\author{
Enmanuel Leonardo Galarza Molina \\ egalarza@ucacue.edu.ec \\ https://orcid.org/0000-0002-9514-831X \\ Universidad Católica de Cuenca, Cuenca, Ecuador
}

Artículo recibido 09 de marzo 2021 / Arbitrado y aceptado 02 de abril 2021 / Publicado 04 de mayo 2021

\section{RESUMEN}

Se plantea un análisis del uso de probióticos y acidificantes como alternativa al uso de antibióticos. La producción avícola tiene gran importancia por la gran demanda de carne para abastecer las necesidades de proteína, el rubro de producción puede significar hasta un $78 \%$ en costos, se tiende a encontrar alternativas para maximizar el rendimiento encontrándose como opciones viables productos como prebióticos, probióticos, acidificantes y enzimas utilizados como aditivos sea en el agua de bebida o en el alimento; a los probióticos se los considera como parte de los aditivos, proyectando su uso a futuro muy prometedor tomando en cuenta la intensidad de los sistemas de producción y a las ventajas que estos prometen en el balance microbiológico estos fortalecen los procesos a nivel del tracto gastrointestinal al lograr reducir el $\mathrm{pH}$ permiten un medio adecuado para que se desarrollen principalmente Lactobacillus, al utilizar prebióticos estos ayudaran a los probióticos nutriéndolos y permitiendo su fortalecimiento, los ácidos orgánicos mejoran los procesos digestivos, reducen el $\mathrm{pH}$ del tracto digestivo incrementando la proliferación de lactobacilos y disminuyendo la flora patógena. De esta manera la integridad intestinal es definida como el funcionamiento óptimo del intestino, permitiendo un mejoramiento de los parámetros zootécnicos, los problemas intestinales se evidencian en el aparato digestivo, haciendo que la energía destinada para la producción, sea enviada a las funciones de defensa, el presente artículo de revisión establece una recopilación de estudios con la finalidad de establecer un criterio de alternativas viables para reemplazar a los antibióticos.

Palabras clave: Acidificantes; broiler; probióticos; microvellosidades; intestinales
ABSTRACT

An analysis of the use of probiotics and acidifiers as an alternative to the use of antibiotics is presented. Poultry production is of great importance due to the great demand of meat to supply the protein needs, the production item can mean up to $78 \%$ in costs, there is a tendency to find alternatives to maximize performance, finding as viable options products such as prebiotics, probiotics, acidifiers and enzymes used as additives either in the drinking water or in the feed; probiotics are considered as part of the additives, projecting a very promising future use taking into account the intensity of the production systems and the advantages they promise in the microbiological balance, they strengthen the processes at the level of the gastrointestinal tract by reducing the $\mathrm{pH}$, allowing a suitable environment for the development of Lactobacillus, When using prebiotics, these will help probiotics by nourishing them and allowing their strengthening, organic acids improve digestive processes, reduce the $\mathrm{pH}$ of the digestive tract increasing the proliferation of lactobacilli and decreasing the pathogenic flora. In this way, intestinal integrity is defined as the optimal functioning of the intestine, allowing an improvement of the zootechnical parameters. Intestinal problems are evidenced in the digestive tract, causing the energy destined for production to be sent to the defense functions.

Key words: Acidifying agents; broiler; probiotics; microvilli; intestinal; intestinal

\section{RESUMO}

É apresentada uma análise do uso de probióticos e acidificantes como uma alternativa ao uso de antibióticos. A produção avícola é de grande importância devido à alta demanda de carne para suprir as necessidades de proteína, o item de produção pode significar até $78 \%$ em custos, há uma tendência de encontrar alternativas para maximizar o desempenho, encontrando como opções viáveis produtos como prebióticos, probióticos, acidificantes e enzimas usadas como aditivos tanto na água potável quanto na ração; Os probióticos são considerados como parte dos aditivos, projetando um uso futuro muito promissor levando em conta a intensidade dos sistemas de produção e as vantagens que prometem no equilíbrio microbiológico, fortalecem os processos no nível do trato gastrointestinal reduzindo $0 \mathrm{pH}$, permitindo um ambiente adequado para o desenvolvimento do Lactobacillus, Os ácidos orgânicos melhoram os processos digestivos, reduzem o $\mathrm{pH}$ do trato digestivo aumentando a proliferação de lactobacilos e diminuindo a flora patogênica. Desta forma, a integridade intestinal é definida como o funcionamento ótimo do intestino, permitindo uma melhora nos parâmetros zootécnicos. Problemas intestinais são evidentes no trato digestivo, fazendo com que a energia destinada à produção seja enviada para funções de defesa, este artigo de revisão estabelece uma compilação de estudos com o objetivo de estabelecer um critério de alternativas viáveis para substituir os antibióticos.

Palavras-chave: Agentes acidificantes; frango de carne; probióticos; microvilli; intestinal; intestinal 


\section{INTRODUCCIÓN}

América Latina tiene gran importancia la producción avícola, la efectividad de su desarrollo depende del rendimiento y producción de carne (1), haciéndose necesario lograr un pollo que cumpla con parámetros productivos favorables como son un rápido crecimiento, una buena conversión alimenticia, un rendimiento canal efectivo (2). En tal sentido, con un intestino saludable se logrará un buen desarrollo de las aves (3). La población de microflora benéfica a nivel de tracto gastrointestinal, unida a las enzimas y demás productos gástricos hará que los pollos desarrollen todo su potencial genético (1) en favor de las industrias avícolas, cuyos principales productos obtenidos son carne y huevos, alimentos muy proteicos para suplir la demanda de este nutriente (4).

Desde los aportes de Yapachura et al., se puede identificar que el rubro de producción puede significar hasta un $75 \%$ o $78 \%$ en los costos totales en una explotación (5); por lo tanto, se tiende a encontrar alternativas para maximizar el rendimiento (6). De esta manera, mencionan que al momento de la ingesta alimentaria los animales se exponen a agentes no convencionales y es la túnica del intestino quien actúa como un muro que hace frente a agentes patógenos, por tanto, repoblar la microflora benéfica con productos denominados probióticos fortalecerán esta barrera y beneficiarán la salud intestinal, además de fortalecer el sistema inmunitario ayudando a mejorar la absorción de nutrientes (7).

Los probióticos cumplen la función de repoblar el tracto gastrointestinal (TGI) con una microbiota que vaya a fortalecer el mismo contra organismos tóxicos y estimular la producción de enzimas para que la degradación de los alimentos en nutrientes se vea fortalecida (8). A nivel que avanza la industrialización se requiere mejorar la formulación, por ende, tanto los alimentos balanceados como el agua de bebida deben ser de óptima calidad, pero se cuente o no con este requerimiento es necesario fortalecerlo buscando otras alternativas para mejorar el desempeño productivo, es aquí donde cumplen un papel importante los ácidos orgánicos denominados también acidificantes, quienes actúan para mejorar el desempeño productivo (9).

Los ácidos orgánicos van a fortalecer los procesos a nivel del tracto gastrointestinal al lograr reducir el $\mathrm{pH}$ de manera que permitirán un medio adecuado para que se desarrollen principalmente Lactobacillus (10); de igual forma, al utilizar prebióticos ayudarán a los probióticos nutriéndolos y permitiendo su fortalecimiento (11). Al incluir aditivos, los parámetros productivos se ven fortalecidos (12).

En cambio, los ácidos orgánicos se han incorporado para regular el $\mathrm{pH}$ y favorecer un medio óptimo y entre otros se recomiendan el ácido cítrico, fumárico, entre otros, obteniéndose resultados favorables (13).

\section{METODOLOGÍA}

La presente Investigación documental constituye una revisión sistemática de algunos artículos científicos publicados por varias revistas en plataformas como Scielo 9 artículos, Redalyc. Org 8 documentos, SJR, Sciencie, 1 documento de cada plataforma se citó también algunos manuales para explicar alguna terminología. Las palabras clave para la identificación de artículos fueron Probióticos, Acidificantes y pollos broiler. Para la búsqueda de información bibliográfica se seleccionó 
alrededor de 40 documentos de estudios relacionados con el tema propuesto, se analizó la información contenida en cada uno de ellos, fueron descartados catorce (14) documentos por cuanto al analizar no se acoplaba el estudio a la síntesis bibliográfica que se le quería dar al documento tal es la de un artículo de revisión que sea claro en la explicación de los trabajos sintetizados y finalmente se decidió escoger 26 publicaciones por su relevancia y confiabilidad de la información el objetivo del presente documento es ofrecer al investigador una compilación de varios documentos que permitan formarse un criterio apropiado con estudios realizados sobre el tema propuesto.

\section{DESARROLLO Y DISCUSIÓN}

La obtención de huevos y carne es el principal objetivo de las industrias avícolas, con el fin de brindar el consumo de proteína animal con mejoramientos en la nutrición de las aves (4). El alimento de las aves es el punto clave para una producción eficiente; en una explotación avícola puede significar hasta el $78 \%$ del costo total de producción (5), por lo que es necesario buscar alternativas para brindar un máximo rendimiento a un costo mínimo (6).

Mediante el suministro alimenticio, las aves son expuestas hacia agentes extraños, donde empieza a actuar la túnica intestinal como una barrera natural contra agentes tóxicos y bacterias presentes en la luz del intestino; sin embargo, el suministro de probióticos puede ayudar a mejorar la función de todo el sistema digestivo, particularmente el intestino que es donde se realiza la absorción de nutrientes ayudando a que mejoren los parámetros nutricionales, digestivos, e inmunológicos (7).

La función de los probióticos en los pollos está dirigida al recuento microbiano del tracto gastrointestinal (TGI) e impedir el desarrollo de bacterias toxicas, producir enzimas para mejorar la descomposición de los alimentos y la mejor utilización de los nutrientes (8).

El desarrollo de esta industria hace cada vez más estricto el control de las materias primas que se requieren en la elaboración de raciones alimenticias, y el empleo de algunos productos como los acidificantes que mejoran los indicadores productivos (9). En tanto, los ácidos orgánicos mejoran los procesos digestivos, reducen el $\mathrm{pH}$ del tracto digestivo incrementando la proliferación de lactobacilos y disminuyendo la flora patógena (10); de la misma manera, el uso de algunos extractos de productos como el ajo mejora la eficiencia en la absorción de nutrientes (11).

La inclusión de aditivos se ha convertido en una práctica común en la alimentación de animales, y dentro de estos, las incorporaciones de aditivos enzimáticos mejoran el índice de conversión alimenticia en pollos y su consumo de alimento (12). los probióticos han dejado de ser solamente bacterias benéficas y se han trasformado en sustancias que actúan contra la colonización de bacterias perjudiciales (14). En este contexto tenemos los probióticos como las sustancias más prometedoras del futuro, siendo una tendencia actual en los sistemas intensivos, notándose un aumento en su utilización en los últimos años debido a los beneficios que genera en el balance microbiano en el tracto gastrointestinal (TGI) (15).

En la industria avícola los acidificantes se vienen usando desde 1981, fecha en la que se recomendaban los ácidos cítrico y fumárico en soluciones del 4,5\% (13). Sin embargo, los resultados han sido variables, debido a que se tiene la inquietud que los ácidos orgánicos de diversa longitud como el 
ácido propiónico, butírico, acético, fórmico, láctico, málico, tartárico y cítrico, cuando se dan con el alimento, cumplen con la función de bacteriostáticos en menor concentración y actúan como bactericidas en altas concentraciones, su actividad varía según el ácido orgánico que se esté utilizando (16).

Los acidificantes pueden ser orgánicos o inorgánicos y tienen como principal función brindar un balance microbiano en el tracto digestivo, mejorando la calidad y disponibilidad de los nutrientes. Los hidratos de carbono suministrados en la dieta son fermentados produciendo ácidos orgánicos endógenos que en combinación con estos aditivos permitirán alterar favorablemente el desarrollo y colonización de microorganismos del intestino, así como también el desarrollo en animales monogástricos (9). Los acidificantes de tipo orgánico, son sustancias que tienen en su estructura el grupo carboxilo $(-\mathrm{COOH})(1)$.

Los ácidos orgánicos son sustancias benéficas en el tracto digestivo impidiendo quedarse como residuos en los productos animales (17). Los mecanismos de acción de los ácidos orgánicos en la microflora intestinal se evidencian de dos formas: la primera ocurre cuando los microorganismos patógenos de los géneros Clostridium, Escherichia y Salmonella se ven afectados mediante la reducción del $\mathrm{PH}$ del alimento y del tracto digestivo y la segunda por la alteración de procesos de los microorganismos como los gram negativos mediante un efecto especifico antimicrobiano (9). El uso de los ácidos orgánicos como el ácido fórmico y propiónico disminuyen la presencia Salmonella brindando beneficios en la producción. Además, el uso de acidificantes permitirá controlar bacterias patógenas y no patógenas (17).
La estructura del sistema digestivo de los órganos tubulares de las aves está conformada por cuatro túnicas concéntricas con características histológicas y funcionales distintas denominadas: mucosa, submucosa, muscular y serosa. De la región anterior a la posterior las estructuras tubulares que componen el sistema digestivo de las aves son: cavidad oral, esófago, proventrículo, molleja, intestino delgado, colon, buche y ciego, estando también conectadas dos glándulas anexas el hígado y el páncreas (18).

La integridad intestinal es definida como el funcionamiento óptimo del intestino, permitiendo un mejoramiento de los parámetros zootécnicos, los problemas que afecten al intestino en el pollo se ven evidenciados en el aparato digestivo, haciendo que la energía destinada para la producción de huevos y carne sea enviada a las funciones defensivas del pollo (19). Se considera al tracto digestivo saludable cuando la población microbial es equilibrada y las secreciones de enzimas digestivas obtienen un buen desempeño de acuerdo al potencial de energía del pollo (20).

La capa epitelial del intestino puede ser afectada por virus, hongos, bacterias, parásitos y / o toxinas, por lo tanto, en el tracto gastrointestinal ocurrirán diversas reacciones como la degradación de la capa de moco, destrucción de las células epiteliales, la interrupción del suministro vascular o la afección del sistema inmunológico teniendo como consecuencia la perdida de la integridad intestinal (21).

Algunos factores adversos pueden alterar la estabilidad del animal y ocasionar problemas de estrés y desequilibrios nutricionales; entre estos tenemos las vacunaciones, el suministro 
de antibióticos y la presencia de sustancias que alteran el valor del $\mathrm{pH}$; razón por la cual se recomienda mantener un equilibrio constante durante la etapa productiva (22).

Las vellosidades intestinales son estructuras de la pared del intestino delgado donde se produce la absorción de los nutrientes; funcionan como proyecciones transversales de las capas celulares, su tamaño puede ser hasta de 1 milímetro, junto a estas también están las microvellosidades intestinales que son filamentos microscópicos que funcionan juntas para que se dé un máximo de absorción. También en la base inferior del intestino están las criptas de Lieberkühn, las cuales son unas depresiones glandulares que se encargan de realizar la secreción de las enzimas que participan en la digestión proceso que se da en los intestinos (23).

Los cambios morfométricos de longitud, ancho de las vellosidades intestinales se miden en un microscopio en aumento de 10X luego de fijar la muestra mediante un corte histológico (24). Una de las tácticas que se presentan para optimizar los entornos utilizables del tracto gastrointestinal (TGI) de los pollos de engorde es la suplementación con aditivos alimenticios como es el caso de las levaduras (25). Así también, los probióticos y prebióticos funcionan como una alternativa al remplazo de los antibióticos que tradicionalmente se han venido utilizando, con la ventaja que no son residuales ni en la carne ni en el huevo por ende no generan riesgo de resistencia en la microbiota humana (26).

\section{Discusión}

La estructura del sistema digestivo de los órganos tubulares de las aves está conformada por cuatro túnicas concéntricas con características histológicas y funcionales distintas denominadas: mucosa, submucosa, muscular y serosa. De la región anterior a la posterior las estructuras tubulares que componen el sistema digestivo de las aves son: cavidad oral, esófago, proventrículo, molleja, intestino delgado, colon, buche y ciego, estando también conectadas dos glándulas anexas el hígado y el páncreas (18).

Lasvellosidadesintestinalessonestructuras de la pared del intestino delgado donde se produce la absorción de los nutrientes, las que funcionan como proyecciones transversales de las capas celulares y su tamaño puede ser hasta de 1 milímetro. También, en la base inferior del intestino, están las criptas de Lieberkühn, las cuales son depresiones glandulares que se encargan de realizar la secreción de las enzimas que participan en la digestión proceso que se da en los intestinos (23).

Entre las estrategias desarrolladas para mejorar las condiciones funcionales del tracto gastrointestinal (TGI) de las aves se encuentra el empleo de nuevos aditivos funcionales alimenticios, y dentro de estas posibilidades está el uso de levaduras (13) así como también los probióticos y prebióticos funcionan como una alternativa al remplazo de los antibióticos (26).

Los probióticos cumplen con la función de repoblar el tracto gastrointestinal (TGI) con una microbiota que vaya a fortalecer el mismo, contra organismos tóxicos y estimular la producción de enzimas para que la degradación de los alimentos en nutrientes se vea fortalecida (8), estos van a fortalecer los procesos a nivel del tracto gastrointestinal al lograr reducir el $\mathrm{pH}$ para permitir un medio adecuado para que se desarrollen principalmente Lactobacillus (10). 
En la industria avícola los acidificantes se vienen usando desde 1981, se recomendaban los ácidos cítrico y fumárico en soluciones del $4,5 \%$ cuando se dan con el alimento cumplen con la función de bacteriostáticos en menor concentración y actúan como bactericidas en altas concentraciones, su actividad varía según el ácido orgánico que se esté utilizando (16).

\section{CONCLUSIÓN}

La utilización de probióticos y ácidos orgánicos como aditivos en la alimentación de aves y tienen como principal función brindar un balance microbiano en el tracto digestivo, primordialmente bacterias benéficas, mejorando la calidad y disponibilidad de los nutrientes. Proteínas, hidratos de carbono, y otros los que suministrados en la dieta son fermentados produciendo ácidos orgánicos endógenos que en combinación con estos aditivos permitirán alterar favorablemente el desarrollo y colonización de microorganismos del intestino, permitiendo de esa manera mejorar la salud intestinal al lograr un desarrollo adecuado de las microvellosidades intestinales las mismas que permiten un mejor aprovechamiento del alimento de esta manera los parámetros productivos se ven favorecidos.

\section{REFERENCIAS BIBLIOGRÁFICAS}

1. Sánchez Silva $M$, Carcelén $C F$, Ara GM, Gonzáles VR, Quevedo GW, \& Jiménez AR. Efecto de la suplementación de ácidos orgánicos sobre parámetros productivos del cuy (Cavia porcellus). Rev. Investig. Vet. Perú, 2014; 25(3): 381-389.

2. Rois $D$, Rivero $C J$, Fernández $M$, Justo $J R$, López C, Lorenzo JM, Lama J, García Fontan MC, Franco D, Arias A, Feijóo J, \& Adán S. Crecimiento de pollos Mos en diferentes estaciones del año: comparación con una estirpe industrial. Scielo, 2011;60(231): 4.
3. Climent F. La Integridad Intestinal: Factores asociados a su mantenimiento. Selecciones Avicolas, 2008;16p.

4. Farrell D. Función de las aves de corral en la nutrición Humana. Revisión Del Desarrollo Avicola. 2013; http://www.fao.org/3/a-i3531s. pdf

5. Yapuchura Saico CR, Mamani Choque SE, Quispe DP, Flores Mamani E. Curvas de crecimiento y eficiencia en la alimentación de truchas arcoiris (Oncorhynchus Mikyss) en el costo de producción. Comunicación, 2018;9(1):10.

6. Aguilera Díaz A. El costo-beneficio como herramienta de decisión en la inversión en actividades científicas. Cofin Habana, (2017); 11(2):322-343.

7. Chávez LA, López A, y Parra JE Crecimiento y desarrollo intestinal de aves de engorde alimentadas con cepas probióticas. Archivos de Zootecnia, (2016); 65(249):51-58.

8. Barrera Barrera HM, Rodríguez González SP, y Torres Vidales G. Efectos de la adición de ácido cítrico y un probiótico comercial en el agua de bebida, sobre la morfometría del duodeno y parámetros zootécnicos en pollo de engorde. Orinoquia, 2014;18(2):52-62.

9. Álvarez Perdomo, GR, Arana Manjarres RS, Franco Cedeño FJ, Zambrano Barros NA, Cangá Morán EE, Ramírez De La Ribera, JL, \& Chacón Marcheco E. Empleo de acidificantes intestinales en la producciónde pollos de ceba. Revista Electronica de Veterinaria, 2017; 18(12):1-9.

10. Guarner, F. (2007). Papel de la flora intestinal en la salud y en la enfermedad. Scielo, 22(2), 6.

11. Hortúa López, L., y Botía Carreño W. Extracto de ajo como alternativa a los promotores de crecimiento en pollos de engorde. Conexion Agropecuaria, 2012;2(2), 35-43.

12. Bertsch A, y Dominguez G. Caracterización de Aditivos Enzimáticos Obtenidos por Monocultivo (Aspergillus niger) y Cocultivo (Aspergillus nigerSaccharomyces cerevisiae) y su Efecto sobre 
el Comportamiento Productivo de Pollos de Engorde. Revista de La Facultad de Ciencias Veterinarias UCV, 2010; 51(1):27-35.

13. Hidalgo K, Rodríguez $B$, Valdivié $M$, y Febles M. Utilización de la vinaza de destilería como aditivo para pollos en ceba. Revista Cubana de Ciencia Agrícola, 2009;43(3): 281-284.

14. López Acevedo EA, Aguirre Guzmán G, y VázquezSaucedaM...Probióticos, una herramienta en la producción pecuaria y acuícola. Scientia Agropecuaria, 2013; 4:129-137.

15. Blajiman JE, Zbrun MV, Astesana DM, Berisvil $A P$, Scharpen AR, Fusari MR, Soto LP, Signorini MM, Rosmini MR, Frizzo LS. Probióticos en pollos parrilleros: una estrategia para los modelos productivos intensivos. Revista Argentina de Microbiologia, 2015; 47(4):360-367.

16. Fatufe A, y Matanmi I. Efecto de probióticos, ácidos orgánicos o su mezcla sobre el rendimiento de crecimiento de gallos de partida. Archivos de Zootecnia, 2011; 60(229): 4.

17. Gonzáles AS, Icochea DI, Reyna SP, Guzmán GJ, Cazorla MF, Lúcar J, Carcelén F, y San Martín V. Efecto de la suplementación de ácidos orgánicos sobre los parámetros productivos en pollos de engorde. Scielo, 2013;24(1):6.

18. Furlan R, Marcari M, y Gonzalez E. Fisiología aviar. Estructura funcional del tracto digestivo. 2002.

19. Faus C. La integridad intestinal: factores asociados a su mantenimiento. Selección Avicola, 2008;11-16.

20. Arce Menocal J, Ávila González E, y López Coello C. Comportamiento productivo y cambios morfológicos en vellosidades intestinales del pollo de engorda a 21 días de edad con el uso de paredes celulares del Saccharomyces cerevisiae. Veterinaria México, 2008; 39(2):6.

21. Salvo Romero E, Alonso Cotoner C, Pardo Camacho C, Casado Bedmar M, y Vicario M. Función barrera intestinal y su implicación en enfermedades digestivas. Revista Española de Enfermedades Digestivas, 2015; 107(11):686-696.

22. Huerta Jiménez $M$, Ortega Cerrilla $M E$, Cobos Peralta M, Herrera Haro JG, Díaz-Cruz A, y Guinzberg Perrusquía R. (2005). Estrés oxidativo y el uso de antioxidantes en animales domésticos. 2005; 30(12);728-734.

23. Gonzáles Mora R. (2016). Vellosidades intestinales: histología, funciones. Lifeder. Com. https://www.lifeder.com/vellosidadesintestinales/

24. Rodríguez González S, Torres Vidales G, Hortúa López L, y Madrigal K. (2017). Evaluación del desarrollo morfo métrico duodenal y los parámetros zootécnicos al suministrar diferentes porcentajes de saccharomyces cerevisiae en la dieta de pollos de engorde. Universidad De Zulia, 27(4).

25. López N, Afanador G, y Ariza CJ. (2008). Evaluación del efecto de la suplementación de levaduras sobre la morfometria de vellosidades intestinales y productos de la microflora en pollos. Revista de La Facultad de Medicina Veterinaria y de Zootecnia, 55(2), 63-76.

26. Díaz López EA, Ángel Isaza J, \& Ángel BD. (2017). Probióticos en la avicultura: una revisión. Revista de Medicina Veterinaria, 35, 175-189. 